\title{
FACEBOOK MARKETING DALAM KOMUNIKASI PEMASARAN MODERN
}

\author{
Zainal Muttaqin 1 \\ ${ }^{1}$ Jurusan Sistem Informasi Fakultas Teknik \\ Universitas Pesantren Tinggi Darul 'Ulum (Unipdu) Jombang \\ Kompleks Ponpes Darul 'Ulum Rejoso Peterongan Jombang Jatim 61481 \\ Email: 1dandy@unipdu.ac.id
}

\begin{abstract}
ABSTRAK
Pemasaran adalah salah satu perangkat vital dalam suatu bisnis, sistem pemasaran yang baik merupakan pendukung siklus hidup sebuah produk (product lifecycle). Pemasaran tidak sekedar pengembangan produk yang baik, penetapan harga yang menarik, dan ketersediaan bagi konsumen sasaran. Perusahaan juga harus berkomunikasi dengan konsumen. Kendala yang dihadapi adalah pada efisiensi anggaran untuk media komunikasi pemasaran. Teknologi informasi khususnya internet sangat mempengaruhi dunia marketing, bahkan pemanfaatan internet untuk marketing dianggap sebagai trend setter. Facebook Marketing merupakan salah satu cara pemasaran melalui internet dengan memanfaatkan fungsi-fungsi yang ada pada jejaring sosial Facebook. Dengan Facebook Marketing pengusaha tidak hanya melaksanakan proses bisnis pemasaran, namun juga dapat berkomunikasi dengan pelanggan-pelanggannya. Facebook Marketing merupakan solusi komunikasi pemasaran modern.
\end{abstract}

Kata kunci : komunikasi, pemasaran, jejaring sosial, facebook, internet

\begin{abstract}
Marketing is one of the vital tools in a business, a good marketing system is a supporter of the life cycle of a product (product lifecycle). Marketing is not just a good product development, attractive pricing, and availability for target consumer. Companies also need to communicate with consumers. Constraints faced by the media on the efficiency of the budget for marketing communications. Especially information technology is affecting the world of internet marketing, even the use of internet for marketing is considered as a trend setter. Facebook Marketing is a way of marketing through the Internet by leveraging the existing functions of the social network Facebook. With Facebook Marketing entrepreneurs do not only carry out the business processes of marketing, but also can communicate with its customers. Facebook marketeing is a modern marketing communications solutions.
\end{abstract}

Key words: communication, marketing, social networking, facebook, internet

\section{Pendahuluan}

Dunia usaha merupakan kelompok pelaku ekonomi terbesar dalam perekonomian Indonesia dan terbukti menjadi katup pengaman perekonomian nasional dalam masa krisis, terlebih sektor usaha mikro, kecil dan menengah yang terbukti mampu menjadi dinamisator pertumbuhan ekonomi pasca krisis ekonomi. Selain menjadi pelaku ekonomi yang paling besar kontribusinya terhadap pembangunan nasional, keberadaan perusahaan juga telah menciptakan peluang kerja yang cukup besar bagi tenaga kerja dalam negeri, sehingga sangat membantu upaya mengurangi pengangguran.

Salah satu kunci keberhasilan dunia usaha adalah tersedianya pasar yang jelas bagi produk mereka. Sementara itu kelemahan mendasar yang dihadapi adalah dalam bidang pemasaran dengan orientasi pasar rendah, lemah dalam persaingan yang kompleks dan tajam serta tidak memadainya infrastruktur pemasaran.

Menghadapi mekanisme pasar yang makin terbuka dan kompetitif, penguasaan pasar merupakan prasyarat untuk meningkatkan daya saing. Oleh karena itu, peran teknologi diperlukan dalam mendorong keberhasilan perusahaan untuk memperluas akses pasar melalui pemanfaatan teknologi informasi berbasis web yang dapat digunakan sebagai media komunikasi pemasaran modern.

Salah satu gagasan pemberdayaan usaha di era teknologi informasi sekarang ini adalah melalui pembuatan media pemasaran berbasis web serta pemanfaatan social networking, media sosial yang dimaksud adalah Facebook Marketing. Media pemasaran berbasis web ini diperuntukan bagi perusahaan dalam mempromosikan usahanya, jalur akses informasi produk, melakukan transaksi usaha, serta melakukan komunikasi bisnis lainnya secara global, dalam rangka memperluas jaringan usahanya, serta dipercaya memiliki efisiensi anggaran yang cukup hemat. 


\section{Komunikasi Pemasaran Modern}

Pemasaran adalah proses sosial dan manajerial dimana individu dan kelompok mendapatkan kebutuhan dan keinginan mereka dengan menciptakan, menawarkan dan menukarkan produk yang bernilai bagi orang lain (Kotler, 2008). Secara umum, tujuan sistem pemasaran adalah sebagai berikut :

a. Memaksimumkan konsumsi

b. Memaksimumkan utilitas (kepuasan) konsumsi

c. Memaksimumkan pilihan

d. Memaksimumkan mutu hidup, kualitas, kuantitas, ketersediaan, harga, lingkungan

Pemasaran modern memerlukan lebih dari sekedar pengembangan produk yang baik, penetapan harga yang menarik, dan ketersediaan bagi konsumen sasaran. Perusahaan juga harus berkomunikasi dengan konsumen, dan subyek yang dikomunikasikan harus membuka peluang (Mahfoedz, 2010). Arah baru tren pemasaran di Indonesia dapat digambarkan dengan 6 hal sebagai berikut:

a. Pelanggan semakin kritis

b. Pelanggan ingin mendapatkan layanan prima

c. Pelanggan memiliki daya beli

d. Pelanggan ingin lebih diperhatikan

e. Situasi persaingan semakin kompetitif

f. Pengguna internet terus meningkat

Jenu Widjaja Tandjung (2011) mengatakan bahwa pemasaran dan pelayanan prima tidak dapat dipisahkan, dan kedua hal tersebut saat ini dapat diakomodir oleh internet. Tandjung menambahkan pengguna internet semakin meningkat dari tahun ke tahun, khususnya kalangan anak muda, dan kondisi seperti ini harus diimbangi oleh pemasar dengan membuat website 2.0, dimana pelanggan dapat memperoleh informasi dan melakukan komunikasi dengan lebih cepat dan murah.

Pemilihan media dalam melaksanakan komunikasi pemasaran sangat menentukan dalam keberhasilan pemasaran. Tahapan memilih media adalah memutuskan jangkauan, frekuensi, dan dampak yang diinginkan. Perlu langkah perencanaan dalam menetapkan media pemasaran yang didasarkan pada beberapa keputusan penting, yaitu :

a. Khalayak sasaran (Segmentasi Pasar)

b. Wilayah demografis (Jangkauan)

c. Waktu yang tepat (Relevansi)

d. Efektifitas materi untuk dikomunikasikan

Media komunikasi pemasaran oleh Machfoedz (2010) diklasifikasikan menjadi 4, yaitu: media elektronik (televisi, radio dan internet), media cetak (surat kabar, majalah, dll.), media luar ruangan dan media lain.

Televisi dianggap sebagai media yang paling tepat untuk aktivitas pemasaran (promosi dan periklanan), namun seiring dengan perkembangan teknologi informasi, internet yang merupakan jejaring informasi internasional mampu menjadi media pemasaran yang andal, bahkan dikatakan oleh Jenu Widjaja Tandjung (2011) dengan internet dapat memberikan efisiensi anggaran pemasaran, internet memiliki jangkauan yang luas, akses mudah dan biaya murah.

\section{Facebook Marketing}

\subsection{Sistem Informasi Pemasaran}

Sistem Informasi merupakan suatu sistem yang tujuannya menghasilkan informasi. Informasi adalah data yang diolah menjadi bentuk yang lebih berguna bagi pemakainya (Fatichah, 2005). Menurut Jogiyanto (2009) agar dapat berguna (berkualitas), maka informasi harus didukung oleh tiga pilar sebagai berikut: sesuai dengan kebutuhan (relevance), tepat waktu (timelines) dan tepat nilainya atau akurat (accurate).

Sistem Informasi Pemasaran adalah sistem informasi yang mendukung perencanaan, kontrol dan pemrosesan transaksi yang dibutuhkan untuk penyelesaian aktivitas pemasaran seperti penjualan, advertising dan promosi. Output yang disajikan oleh sistem informasi pemasaran dikenal dengan istilah 4P yang terdiri dari product (produk), place (tempat), promotion (promosi) dan price (harga) (Jogiyanto, 2009). Sistem informasi pemasaran tidak hanya digunakan internal perusahaan/organisasi, namun juga dapat dimanfaatkan sebagai sistem informasi yang menjangkau ke pelanggan (eksternal). Aktivitas yang dikerjakan adalah penjualan produk ke pelanggan melalui sistem informasi, dapat berupa website e-commerce. 


\subsection{E-Commerce}

Teknologi informasi khususnya internet sangat mempengaruhi dunia marketing, bahkan pemanfaatan internet untuk marketing dianggap sebagai trend setter. Semakin tingginya penggunaan internet berbanding lurus dengan pemanfaatannya di dunia marketing, sehingga dikatakan bahwa marketing online mulai populer sejalan dengan makin pupulernya penggunaan internet (Lasmadiarta, 2011).

Hal ini terbukti dengan banyaknya usaha mulai mencoba menawarkan berbagai macam produknya dengan menggunakan media internet. Hal ini telah berdampak pada kokohnya keyakinan pelaku usaha terhadap pentingnya peranan teknologi dalam pencapaian tujuan financial perusahaan melalui modifikasi dan efisiensi proses bisnis, yaitu dengan menggunakan E-Commerce.

Ada beberapa istilah untuk E-Commerce yaitu Internet Commerce atau Ecom atau E-Commerce atau Immerce, semua sebutan diatas mempunyai makna yang sama. Istilah-istilah tersebut berarti membeli dan/atau menjual secara elektronik (Wahana Komputer, 2006).

E-Commerce merupakan salah satu keunggulan dari internet. Dengan E-Commerce penjual dan pembeli dapat bertemu di dunia maya dengan perantara sebuah website, sehingga dapat melakukan transaksi tanpa batas ruang dan waktu, hingga akhirnya di era sekarang ini tiada hari yang terlewatkan tanpa mendengar atau membaca istilah E-Commerce di berbagai media informasi, termasuk dalam jejaring sosial (social networking).

\subsection{Facebook Marketing}

Setelah Search Engine Optimization (SEO) sudah dianggap tidak cukup untuk melakukan efektifitas pemasaran di internet, maka lahirlah Web 2.0 atau yang lebih dikenal dengan social media. Diantara sosial media yang populer adalah Facebook, Youtube, Flickr, Twitter, dll. Dari sinilah muncul istilah SMO (Social Media Optimization) yang merupakan teknik baru dalam marketing online, namun bukan berarti teknik lama (SEO) tidak berlaku lagi. Menggabungkan teknik SEO dan SMO untuk aktivitas marketing secara online akan memberi hasil yang luar biasa (Lasmadiarta, 2011).

Facebook didirikan pada 4 Pebruari 2004, telah mencatatkan lebih dari 37 juta pengguna serta ribuan jaringan bisnis. Facebook telah mengembangkan berbagai ragam aplikasi yang dapat diinstall para pengguna. Aplikasi-aplikasi inilah yang memberikan nilai tambah bagi Facebook. Aplikasi yang dikembangkan banyak yang mendukung bisnis dan pekerjaan seperti menjual atau membeli barang (Muklason dan Aljawiy, 2011).

Menjamurnya jejaring sosial seperti Facebook ini membuka peluang yang sangat baik bagi siapa saja untuk melakukan aktivitas marketing dengan lebih baik dan berbiaya relatif murah (Lasmadiarta, 2011). Aktivitas marketing dan proses bisnis lainnya dengan menggunakan jejaring sosial Facebook dapat disebut juga sebagai E-Commerce.

Facebook marketing adalah melakukan aktivitas marketing menggunakan semua fasilitas yang disediakan oleh facebook dengan tujuan meningkatkan penjualan (sales) dan menjalin komunikasi yang lebih langgeng dengan pelanggan (customer relationship). Konsep Facebook Marketing dapat digambarkan pada Gambar 1.

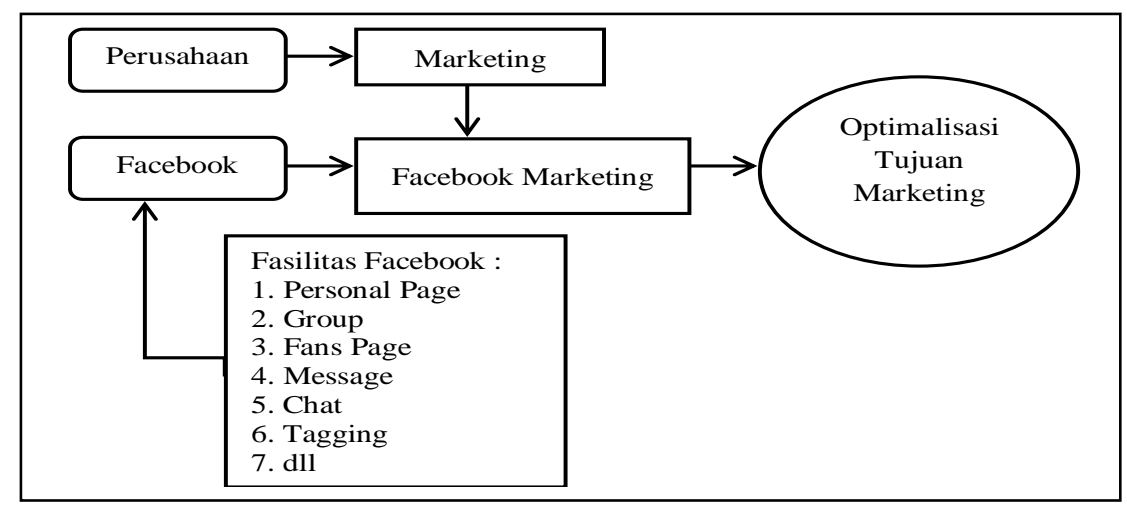

Gambar 1. Konsep Facebook Marketing 
Tujuan marketing atau beberapa hal yang dapat dilakukan dalam Facebook marketing adalah sebagai berikut :

\section{a. Communitization}

Pembentukan komunitas yang terdiri dari orang-orang yang memiliki kepentingan dan ketertarikan yang sama yang terkait dengan produk anda.

b. Clarification

Membentuk persepsi tentang siapa dan apa produk kita di benak konsumen. Disamping itu dalam Clarification kita harus mampu menjawab dan memperjelas jika ada konsumen yang masih bingung atau memiliki persepsi yang berbeda tentang siapa dan apa produk kita.

c. Commercialization

Terjadinya penjualan kemudian membangun hubungan yang berkelanjutan.

d. Connection

Menjaga hubungan agar selalu dekat dengan pelanggan, melalui kedekatan ini dapat tercipta penjualan yang berkelanjutan.

e. Characterization

Meningkatkan brand awareness atau kesadaran terhadap merk, sehingga konsumen dapat dengan mudah mengingat, mengenali dan membedakan dengan jelas produk kita dengan produk yang lain.

f. Conversation

Membicarakan atau menyebarkan informasi kepada komunitas tentang apa yang kita lakukan, sehingga konsumen turut serta mempromosikan produk kita kepada konsumen lainnya.

g. Combination

Gabungan dua atau lebih tujuan dari Facebook marketing.

Tujuan Facebook Marketing tersebut ditujukan agar perusahaan memiliki kemampuan untuk menguasai pasar. Penguasaan pasar dapat dipandang sebagai salah satu indikator keberhasilan. (Riana dan Baladina, 2008). Tujuan perusahaan pada umumnya adalah mempertahankan atau meningkatkan tingkat market share. Sehingga pencapaian tujuan berarti juga dianggap sebagai keberhasilan perusahaan.

\section{Implementasi Facebook Marketing Dalam Komunikasi Pemasaran Modern}

\subsection{Strategi Informasi}

Dalam komunikasi pemasaran, penyampaian informasi menjadi aktifitas paling penting. Informasi dalam komunikasi disebut juga sebagai pesan (message), dalam menyampaikan pesan, pemasar harus memperhatikan beberapa hal sebagai berikut :

a. Pola Pesan

Menurut Machfoedz (2010), bagian terpenting dari strategi penyampaian pesan pemasaran adalah penetapan cara terbaik untuk mengkomunikasikan pokok pesan kepada khalayak sasaran dalam hal ini adalah konsumen/pelanggan. Beberapa hal yang perlu diperhatikan dalam memberntuk pola pesan adalah sebagai berikut :

- Kemudahan dalam menarik kesimpulan: pesan harus lugas dan eksplisit

- Pesan berisi tunggal atau ganda : pesan tunggal adalah pesan yang disampaikan hanya berisi pandangan satu sisi, misal hanya sisi positifnya saja, sedangkan pesan ganda menyampaikan pandangan dua sisi, positif dan negatif atau kelebihan dan kekurangan produk yang kita tawarkan.

- Tatanan presentasi : mengatur materi dan alur presentasi, mengemukakan pokok-pokok pesan di awal dapat memberikan gambaran kepada konsumen atas apa yang akan diterimanya, sehingga dapat membangun minat audience.

Lasmadiarta (2011) menambahkan bahwa kepercayaan adalah hal yang penting dalam melakukan penawaran, melalui Facebook orang dapat membangun kepercayaan dengan menyampaikan pesan berupa informasi-informasi sebagai berikut :

- Cantumkan informasi tentang profil sebanyak-banyaknya (selama tidak mengganggu privasi)

- Masukkan alamat dan kontak yang bisa dihubungi

- Cantumkan beberapa nama perusahaan rekanan (bila ada)

- Jadilah member dari halaman orang-orang terkenal

- Posting sesuatu yang bermanfaat

- Masukkan foto-foto presentasi yang meyakinkan

- Penyampaian Pesan

Ada 2 faktor yang perlu diperhatikan dalam penyampaian pesan (presentasi), yaitu : isi pesan harus berorientasi pada produk dan tingkat kepedulian konsumen harus terbangun. Hal ini dapat dilakukan dengan cara sebagai berikut : 
- Informasi yang disampaikan harus faktual

- Jangan menimbulkan kekhawatiran konsumen

- Sisipkan humor-humor segar dalam presentasi

- Sertakan gambar-gambar ilustrasi atau animasi

- Yakinkan konsumen bahwa perusahaan anda dapat dipercaya dengan memberikan nomor kontak untuk kemudahan komunikasi di akhir presentasi.

b. Media Penyampaian

Facebook memiliki beberapa fasilitas untuk menyampaikan pesan kepada membernya, dapat melalui message box (kotak pesan), posting status, catatan dan image tagging. Gunakan fasilitas-fasilitas ini secara berkala dan terencana, misal dengan cara 3 hari sekali mengirimkan informasi produk melalui message box, 1 minggu sekali membuat catatan terkait dengan keunggulan produk dan relevansinya dengan kejadian yang faktual, dan seterusnya.

c. Mengatur Penyampaian Pesan

Mengatur frekuensi penyampaian pesan melalui media yang disediakan oleh Facebook memang harus secara berkala dan terencana, adapun cara-caranya adalah sebagai berikut:

- Judul atau Subyek pesan harus menarik

- Lebih baik dikirim secara personal, bukan massal agar tidak dianggap sebagai spam

- Buatlah pesan sesingkat dan sejelas mungkin

- Selalu akhiri dengan kontak anda

- Buatlah jadwal dan frekuensi pengiriman pesan secara berkala

\subsection{Merancang Promosi}

Promosi dilakukan untuk berkomunikasi dan mempengaruhi pelanggan agar dapat menerima produk yang dihasilkan oleh perusahaan. Pemasar dapat merancang promosi dengan berbagai cara, seperi periklanan, promosi penjualan, publisitas penjualan individu dan kemasan yang menarik.

a. Periklanan

Periklanan dapat dilakukan dengan cara menyampaikan pesan kepada konsumen berupa informasi produk, bisa dalam bentuk gambar maupun deskripsi produk.

b. Promosi Penjualan

Promosi Penjualan dilakukan dengan cara membuat agenda promo khusus dalam masa tertentu secara berkala, misalnya menjelang lebaran membuat agenda pemasaran diskon hingga $70 \%$, atau dalam rangka tahun baru pemasar memberikan hadiah langsung berupa produk lain kepada pembeli, dan lain sebagainya.

c. Publisitas Penjualan Individu

Publisitas Penjualan Individu atau Personal Selling adalah menjual secara langsung kepada masingmasing konsumen, ini dapat dilakukan dengan cara berkomunikasi langsung dengan konsumen, baik dengan cara mengirim pesan atau dengan melakukan obrolan.

d. Kemasan Yang Menarik

Kemasan produk atau product packing memiliki daya tarik tersendiri bagi konsumen, semakin menarik kemasan maka konsumen akan semakin tertarik untuk mengetahui produk lebih lanjut, maka penggantian kemasan secara berkala juga dibutuhkan untuk melakukan promosi pemasaran.

\subsection{Membangun Komunitas}

Dengan mengintegrasikan sosial media ke dalam sistem pemasaran, banyak hal yang dapat dilakukan guna meningkatkan efisiensi manajemen hubungan pelanggan (customer relationship management), halhal yang dapat dilakukan dengan facebook untuk adalah sebagai berikut :

a. Memanfaatkan Group Dan Fans Page Melalui Facebook

Group dan Fans Page atau halaman penggemar adalah sebuah layanan yang diberikan oleh Facebook berupa halaman yang berisi informasi umum perusahaan/instansi yang dapat disukai (like) oleh pengguna Facebook secara umum, sehingga pengguna yang menyukai halaman tersebut terkumpul menjadi satu komunitas penggemar. Interaksi yang terjadi adalah ketika pemilik halaman mengirimkan informasi ke halaman tersebut dan/atau salah satu penggemar mengirimkan informasi/komentar di halaman tersebut, maka seluruh penggemar yang tergabung akan menerima informasi yang dikirimkan tersebut, sehingga hal ini dipandang sangat efektif untuk pemasaran.

b. Optimalisasi Facebook Marketing Melalui Aplikasi

Facebook memiliki banyak fitur aplikasi yang dapat dimanfaatkan diantaranya adalah untuk mengadakan sebuah pooling (jajak pendapat). Dengan aplikasi jajak pendapat ini, pemilik usaha/instansi akan mendapatkan umpan balik (feedback) dari pelanggannya secara acak, sehingga hasil dari jajak pendapat tersebut dapat digunakan untuk menentukan kebijakan selanjutnya. 


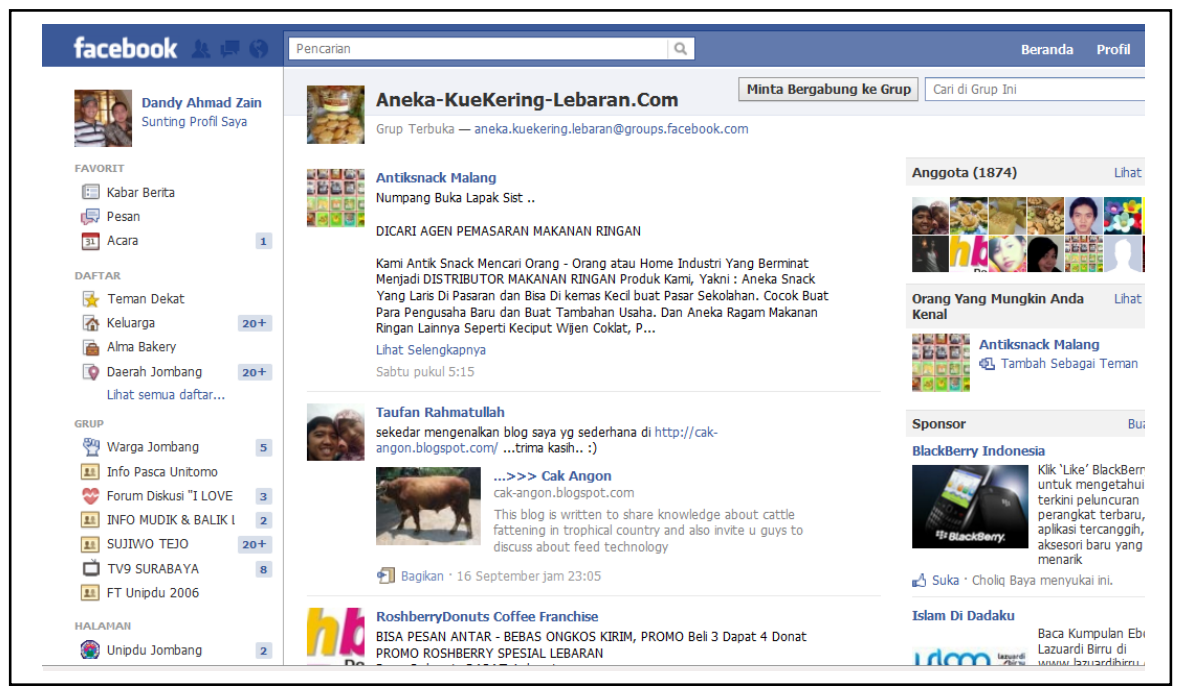

Gambar 2. Contoh Grup Facebook Untuk Pemasaran Kue Kering (Facebook,2012)

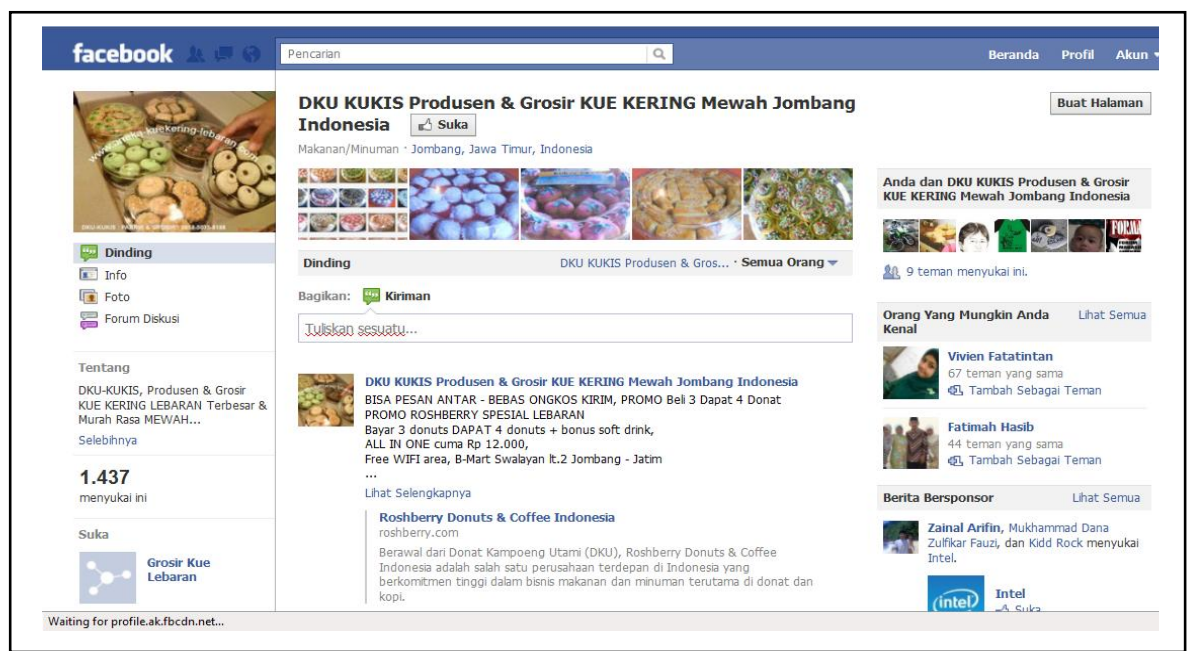

Gambar 3. Contoh FansPage Facebook Untuk Pemasaran Kue Kering (Facebook, 2012)

\section{Penutup}

Internet semakin mudah diakses dan pengguna internet semakin meningkat. Berdasarkan data dari www.internetworldstats.com, pengguna internet di seluruh dunia hingga 31 Maret 2011 sebanyak 2.095.006.005 atau 30,2\% dari penduduk dunia, dan jumlah ini akan semakin meningkat. Facebook termasuk website yang paling sering dikunjungi dimana Indonesia menempati peringkat kedua terbanyak pengguna Facebook, dengan jumlah pengguna 38.164.520 orang. Sedangkan di Indonesia, Facebook menempati rating pertama mengalahkan google sebagai website yang paling sering dikunjungi. (www.checkfacebook.com, 11-06-2011). Melihat data tersebut beberapa keuntungan yang didapat dengan menggunakan facebook sebagai media pemasaran adalah sebagai berikut:

a. Facebook menyediakan fungsi informasi

Facebook menyediakan kolom untuk mengisi berbagai informasi pemakainya, seperti umur, lokasi, hobi, kegiatan dan informasi lain yang sangat dibutuhkan untuk menentukan segmentasi pasar dalam aktitivitas marketing.

b. Segmentasi pasar lebih fokus

Dengan facebook, dapat dilakukan penyaringan target pasar dengan tepat sasaran berdasarkan informasi yang disajikan penggunanya.

c. Dapat diakses setiap saat

Facebook dapat diakses melalui jaringan internet setiap saat, baik dari komputer maupun dari handphone.

d. Komunikasi jadi lebih mudah

Facebook menyediakan fungsi komunikasi, diantaranya fungsi pesan (message), obrolan (chat) dan lain-lain. 
e. Zero Time Feedback

Feedback atau umpan balik atas produk dapat berupa kritik dan saran dapat disampaikan melalui facebook saat itu juga tanpa merepotkan pengguna.

f. Selalu terhubung

Facebook sebagai alat komunikasi dengan dunia bisnis, sehingga bisnis akan terpelihara dengan baik sepanjang masa.

g. Low Budget, High Impact

Menggunakan Facebook 100\% gratis, sehingga banyak penghematan yang bisa dilakukan.

h. New Wave Marketing

Hermawan Kartajaya, orang yang pernah dinobatkan sebagai salah satu dari 50 guru yang mempengaruhi masa depan marketing dunia, dalam Lasmadiarta (2011) mengatakan bahwa saat ini dunia marketing sudah berubah dan sekarang kita sudah memasuki era New Wave Marketing (gelombang baru pemasaran) dimana Facebook adalah salah satu penyebab utamanya.

\section{Daftar Pustaka}

Aljawiy, A. Y. dan Muklason, A., 2011. Jurnal Ilmiah "Teknologi" : Jejaring Sosial Dan Dampak Bagi Penggunanya, Program studi Sistem Informasi Unipdu, Jombang.

Digibook Technology., 2009. Panen Dolar dari AdSense, AdBrite dan Text Link Ads. Andi Publisher: Yogyakarta.

Fatichah, C., 2005. Analisis dan Perancangan Sistem, PIKTI-ITS, Surabaya.

http://www.checkfacebook.com, diakses pada 11-06-2011, 05.30 WIB.

http://www.internetworldstats.com, diakses pada 11-06-2011, 05.30 WIB.

Jogiyanto., 2009. Sistem Teknologi Informasi: Edisi III. Andi Publisher: Yogyakarta.

Jubilee Enterprise., 2009. Facebook Untuk UKM (Usaha Kecil dan Menengah). Elex Media Komputindo: Jakarta.

Lasmadiarta, M., 2011. Extreme Facebook Marketing for Giant Profits. Elex Media Komputindo: Jakarta.

Machfoedz, M., 2010. Komunikasi Pemasaran Modern. Cakra Ilmu: Yogyakarta.

Rahardjo, B., 2009. Diary Budi rahardjo. Oase Media: Bandung.

Riana, F. D dan Baladina, N., 2008. Teori Pemasaran, Aspek Pasar Dan Strategi Pemasaran Perusahaan Agribisnis. Universitas Brawijaya: Malang.

Tandjung, J. W., 2011. 18 Jurus Ampuh Menyiasati Persaingan Bisnis. Andi Publisher: Yogyakarta.

Wahana Komputer., 2010. Marketing Gratis dengan Facebook. Andi Publisher: Yogyakarta.

Wahana Komputer., 2006. Apa \& Bagaimana E-Commerce. Andi Publisher: Yogyakarta.

Zarrela, D., 2010. The Social Media Marketing Book. Serambi Ilmu Semesta: Jakarta. 